\title{
Investigation of Stretch and Recovery Property of Weft Knitted Regular Rib Fabric
}

\author{
Taslima Ahmed Tamanna \\ Lecturer, Department of Textile Engineering, \\ BGMEA University of Fashion and Technology, Bangladesh \\ Mohammad Abul Hasan Shibly \\ Nurunnabi \\ Md. Suruj-Zaman \\ Lecturer, Department of Textile Engineering, \\ National Institute of Textile Engineering and Research, Bangladesh \\ Bivuti Vusan Mondal \\ Technical Officer, Department of Textile Engineering, \\ National Institute of Textile Engineering and Research, Bangladesh

\section{Palash Kumar Saha} \\ Lecturer, Department of Textile Engineering, Northern University, \\ Bangladesh
}

doi: 10.19044/esj.2017.v13n27p400 URL:http://dx.doi.org/10.19044/esj.2017.v13n27p400

\begin{abstract}
Weft knitted regular rib $(1 \times 1)$ fabric stretch and recovery property are very tough to control. This project and thesis work have been devoted to studying the effect of variation of stitch length, yarn count, and GSM on the stretch and recovery properties of weft knit regular rib fabric. Three yarn counts, each with 4 level of stitch length, was manufactured for the purpose of this experiment, remaining the machine set up, dyeing and finishing process constant. In this research, it was found that the better stretch and recovery property of regular rib fabric can be produced by using $2.6 \mathrm{~mm}$ to $2.65 \mathrm{~mm}$ stitch length for yarn count of Ne 28/1 KH and GSM of 195 to 205.
\end{abstract}

Keywords: Weft knitted regular rib fabric, stitch length, yarn count, stretch and recovery properties, GSM

\section{Introduction}

Knitted fabrics are divided into two main groups; warp and weft knitted fabric. Weft knitted fabric is a most common type of knitted fabric. In this fabric, one continuous thread runs crosswise on the fabric, making all 
of the loops in one course. The weft knitted structure is very different from the warp knitted one. In a weft knitted structure, continuous row of loops can be made by using only one thread. Consequently, there are four basic groups of knitted structure, according to the arrangement of loops in their course and wales. All types of knitted fabrics are derived from those basic structures. The knitted structures are namely: plain/single, rib, purl, and interlock knit structure (Belal, 2009). Rib is also known as 'Double-knit'. The rib is the second family of knit structures. Rib fabric requires two sets of needles; one dial and another cylinder. The two sets of needles are operating between wales of stitches and wales of back stitches of the knitted fabric. Rib fabrics knit on the machine with two sets of the needle and this machine is known as circular rib knitting machine (Spencer, 2001). There are many fabric properties in which stretch and recovery is an important property of rib fabric. Stretch means to lengthen, widen, and distend. Various types of knitted fabrics have different appearance and characteristics. A knitted fabric that have higher wales increase the rigidity and stability in widthwise, while the higher the courses, the higher the rigidity and stability in lengthwise. A knitted fabric having many wales and courses density will have better recovery from stretching than a fabric having lesser wales and courses. Therefore, such fabric that will have fewer wales and courses will be less rigid, stretch more easily, fit to body shape in a better way, but will have poorer recovery ability (Weft knitting fundamentals, 1994). So stretch and recovery property also influence the rib fabric dimensional stability.

\section{Research Objective}

a) To identify the stretch and recovery property of weft knitted regular $(1 \times 1)$ rib fabric with the variation of yarn count and stitch length.

b) To find out the stitch length at which better stretch and recovery property can be achieved.

c) To determine the influence of stitch length on fabric stretch and recovery property.

\section{Materials and Methods Materials}

The experimental set up was planned after selecting fabric's rib structure and stitch length. Rib fabric was knitted in a circular rib knitting machine equipped with 54 feeders, positive feed devices, and adjustable fabric pulley take-down system each with 3 to 4 levels of stitch length. This is remaining the machine set up and yarn count constant at tension $12 \mathrm{cN}$ for all feeders. For each yarn count, three to four different stitch length of fabric was knitted by adjusting the diameter of VDQ pulley. Thus, the plan of the experiment consisted of a total 11 fabrics sample. 


\begin{tabular}{|c|c|c|c|c|}
\hline Fabric Type & $\begin{array}{c}\text { Yarn Count } \\
(\mathrm{Ne})\end{array}$ & $\begin{array}{c}\text { Machine } \\
\text { Diameter }\end{array}$ & $\begin{array}{c}\text { Finish Fabric } \\
\text { Diameter }\end{array}$ & $\begin{array}{c}\text { Stitch Length } \\
(\mathrm{mm})\end{array}$ \\
\hline Regular 1×1 Rib & KH 26/1 & $26^{\prime \prime} \times 24 \mathrm{G}$ & $52^{\prime \prime}$ & $\begin{array}{c}2.70,2.75, \& \\
2.80\end{array}$ \\
\hline Regular 1×1 Rib & KH 28/1 & $26^{\prime \prime} \times 24 \mathrm{G}$ & $52^{\prime \prime}$ & $\begin{array}{c}2.55,2.60, \\
2.65, \& 2.70\end{array}$ \\
\hline Regular 1×1 Rib & KH 30/1 & $26^{\prime \prime} \times 24 \mathrm{G}$ & $52^{\prime \prime}$ & $\begin{array}{c}2.55,2.60, \\
2.65, \& 2.70\end{array}$ \\
\hline
\end{tabular}

Table 1. Three types of fabric specifications

\section{Stretch and Recovery Standard}

Stretch and recovery property of rib fabric should be maintained by the following standard.

\begin{tabular}{|c|c|c|}
\hline \multicolumn{2}{|c|}{ Parameter } & Requirements \\
\hline \multirow{2}{*}{ Stretch properties } & Warp/Length wise (\%) & $20 \%$ (Minimum) \\
\cline { 2 - 3 } & Weft/Width wise (\%) & $170 \%$ (Minimum) \\
\hline $\begin{array}{c}\text { Residual Extension (after 1 minute } \\
\text { and 30 minutes) }\end{array}$ & Warp/Length wise (\%) & $10 \%$ (Maximum) \\
\cline { 2 - 3 } & Weft/Width wise (\%) & $50 \%$ (Maximum) \\
\hline
\end{tabular}

Table 2. Stretch and recovery standard BS 4294:1968 method for regular rib fabric

\section{Methods}

\section{Analysis of Sample}

The sample fabrics were tested by using Testometric machine according to the method BS-4952. At first, $150 \mathrm{~mm} \times 75 \mathrm{~mm}$ fabric was cut out from a large piece of fabric and then sample fabric (gauge length $75 \mathrm{~mm}$ ) was fixed with upper and lower jaw of the Testometric machine. The test was carried out using $3 \mathrm{~kg}$ load. The extension was measured as L1.

In the test for the residual extension, the sample was given one preliminary stretch cycle. Then it extended to a specified force which was held for 10s and in the next cycle, the sample was held for 1 minute. It was removed and allowed to relax on a flat and smooth surface and its length L2 was measured after $1 \mathrm{~min}$ to see how much of its original length was recovered. If the specification is required, the specimen can be measured after 30 minutes and get the length L3. Extension, residual extension after 1 minute and residual extension after 30 minutes are measured.

Above three parameters were used for measuring the stretch and recovery of the regular rib fabric. In addition, the following parameters have a significant influence on stretch and recovery property of weft knitted regular rib fabric: 


\section{Yarn Count}

Yarn count is a numerical expression, which expresses the coarseness or fineness of the fabric i.e., whether the yarn is thick or thin. Carded hosiery (KH) yarn has been used to complete the research. The yarn counts are $\mathrm{Ne}$ 26/1, 28/1, and 30/1.

\section{Stitch Length}

Stitch length is a length of yarn which includes one needle loop and half the sinker loop on either side of it. Generally, the larger the stitch length, the more extensible, lighter the fabric, poorer the cover, capacity, and bursting strength. Stitch length was measured through the following ways:

a) 50 loops were counted at the edge of the fabric along the course direction. Start and end point of the 50 loops were marked on yarn.

b) The 50 loops were then unraveled and straightened to yarn. Straightened yarn length was measured in mm. Finally, the formula below is used to measure stitch length.

Stitch Length $=\frac{\text { Length of yarn (50 loops) }}{50} \mathrm{~mm}$

\section{G.S.M}

The property is self-explanatory which indicates the weight in grams of one square meter fabric. Fabric's GSM is directly related to stitch length. In modern weft knitting machine, there is a positive feeder called IRO which regulates the speed of the fed yarn. If the speed of IRO increases, the quantity of yarn passing in the $\mathrm{m} / \mathrm{c}$ increases. As such, the loop size increases and hence the GSM decreases. The reverse happens and the GSM increases. The loop size can also be decreased by adjusting the distance between the cylinder and the dial needles: If the distance is more, the loop size increases and hence the GSM decreases. Stitch length 』Stitch density 伊abric GSM 亿

Sample fabric GSM was measured by using below formula:

G. S. $M=\frac{\text { Sample weight in } \mathrm{gm}}{\text { Length } \times \text { Width in } \mathrm{mm}} \times 1000 \times 1000$

\section{Machine Gauge (E)}

Machine gauge denotes the number of needles per inch arranged. This is arranged on the needle carrier and based on the nominal machine diameter. The higher the machine gauge, the higher the wales. More wales increase the elastic property of the fabric.

$$
\text { Machine Gauge, } \mathrm{E}=\frac{25.4}{\mathrm{Pitch}} \mathrm{mm}
$$




\section{Determination of Extension and Residual Extension of Fabric}

Extension and residual extension of fabric were measured according to following calculation:

Initial (gauge) Length $=\mathrm{L} \mathrm{mm}$.

Extension $=\mathrm{L}_{1} \mathrm{~mm}$.

$$
\text { Extension } \%=\frac{\text { Extension L1 }- \text { Initial Length L }}{\text { Initial Length L }} \times 100
$$

\section{Results and Discussions}

\section{Result of Extension and Recovery of Regular Rib Fabric for Yarn Ne} 26/1

The extension results were determined according to the method BS4952 with the help of a Testometric machine. The change of extension with stitch length in both length and widthwise is given below:
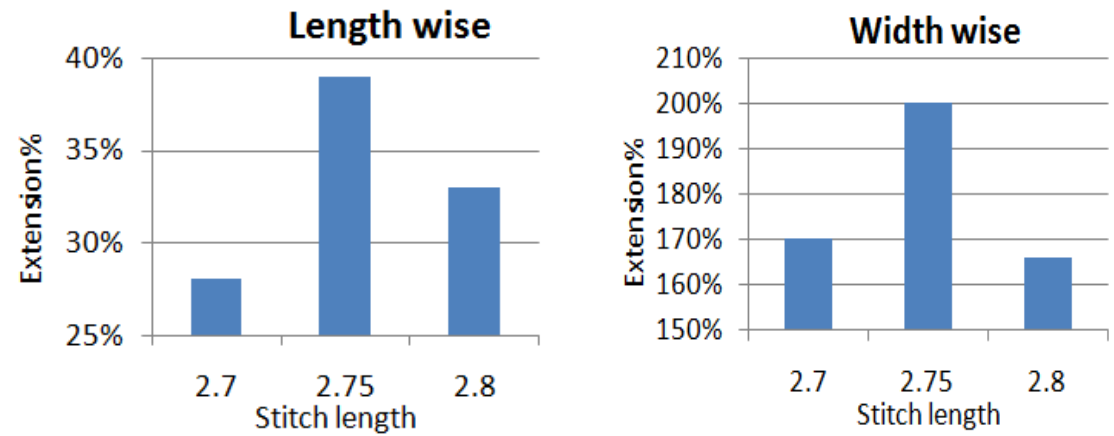

Figure 1. Effect of stitch length on the extension of regular rib fabric at both fabric length and widthwise
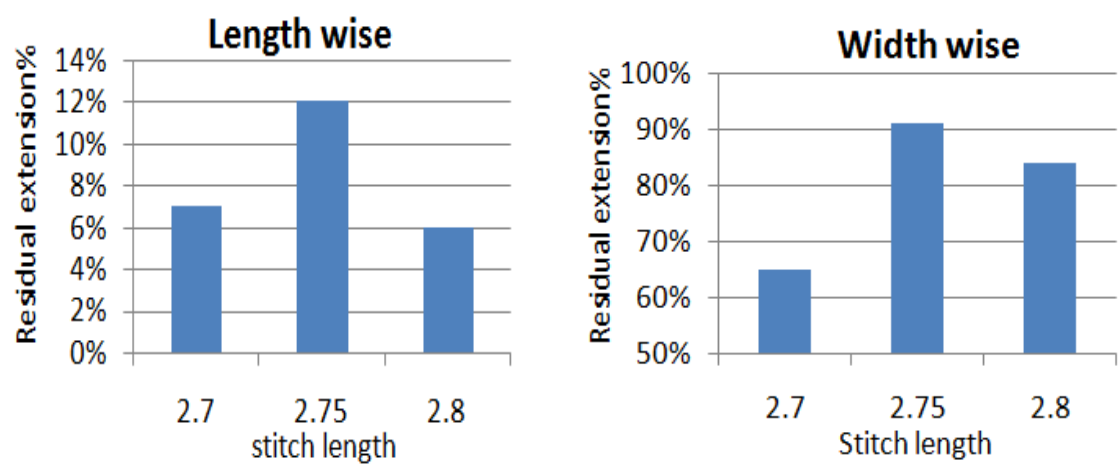

Figure 2. Change of residual extension of rib fabric with stitch length at both fabric length and widthwise after 1 minute 

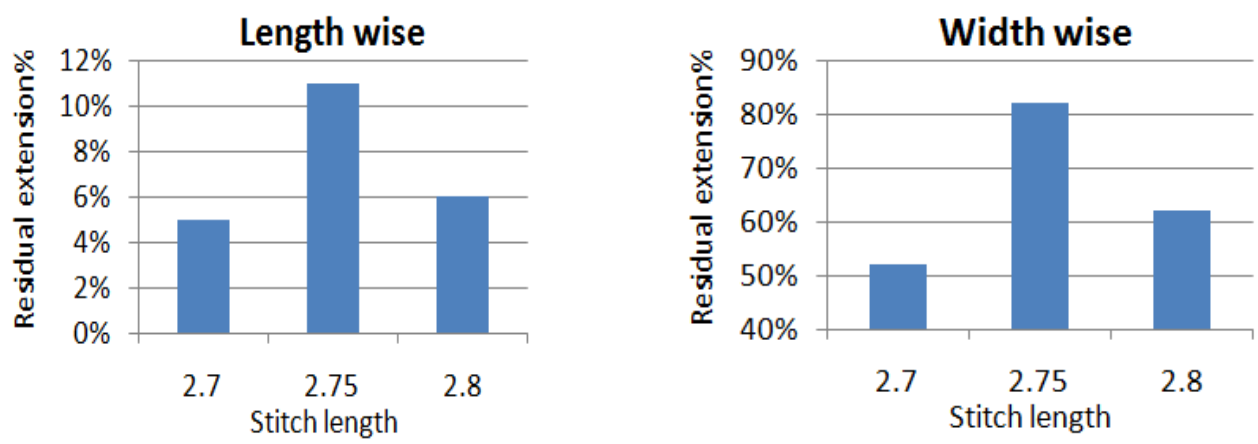

Figure 3. Relationship between stitch length and residual extension after 30 minutes at fabric length and widthwise

Discussion: Graphs showed that the widthwise extension of $1 \times 1$ rib fabric is better than lengthwise. Also, recovery is better in length direction than width direction. The lengthwise extension and residual extension can be achieved at stitch length $2.80 \mathrm{~mm}$. In widthwise, it is better at $2.70 \mathrm{~mm}$ for $\mathrm{Ne} 26 / 1$.

\section{Influence of Different GSM of Same Count Ne 26/1 on Extension and Recovery of Rib Fabric}
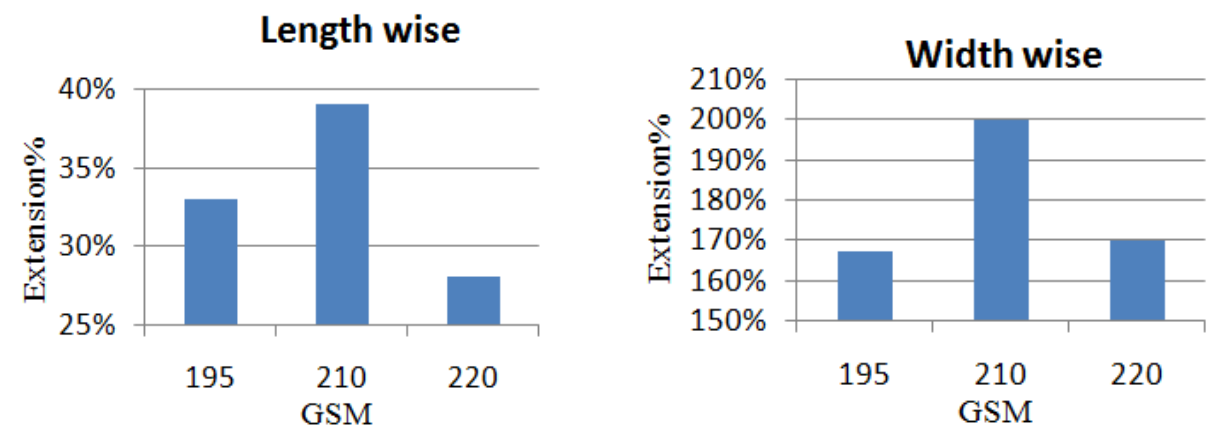

Figure 4. Relationship between GSM and extension in both fabric lengths and widthwise
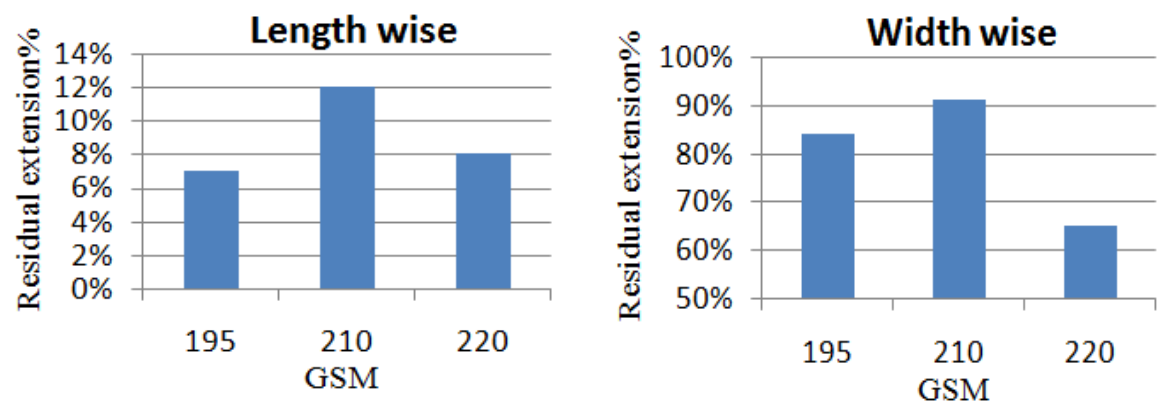

Figure 5. The change of residual extension with GSM after 1 minute 

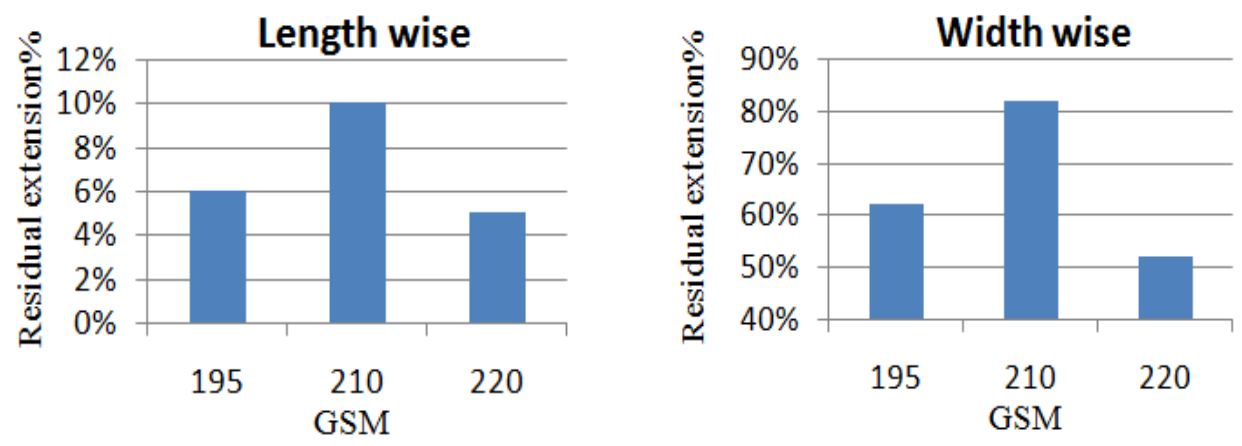

Figure 6. Effect of GSM on the residual extension of regular rib fabric at both fabric length and widthwise after 30 minutes

Discussion: The above graphs show that the width wise extension of $1 \times 1 \mathrm{rib}$ fabrics is better than lengthwise. Also, recovery is better in lengthwise than widthwise. It also showed that in the lengthwise and widthwise, better extension and residual extension can be achieved at GSM 220 in Ne 26/1.

The Changing of Extension and Recovery Property of Fabric with Stitch Length for Yarn Ne 28/1
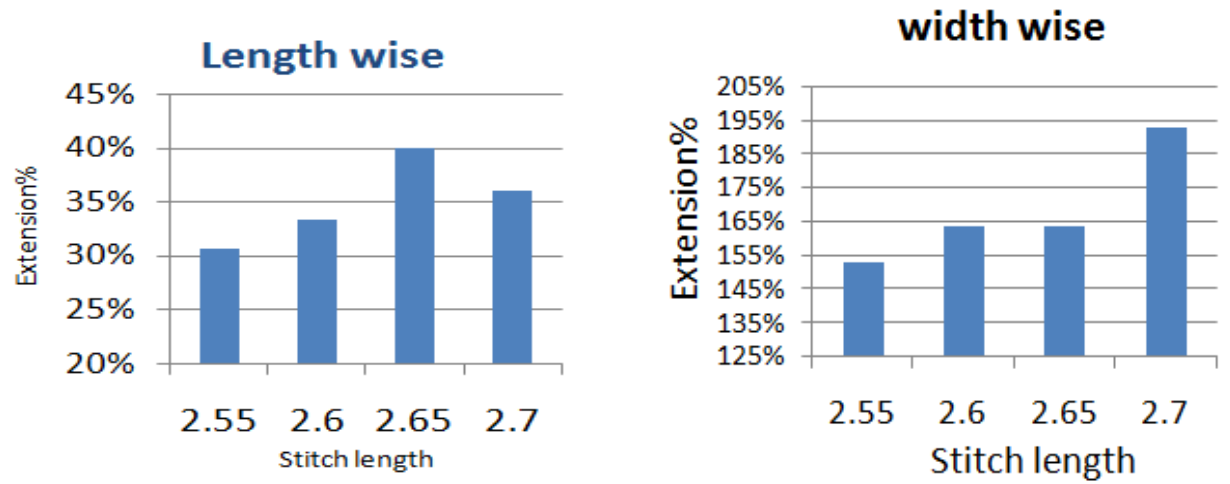

Figure 7. The changing of extension with the different stitch length of $1 \times 1$ rib fabric
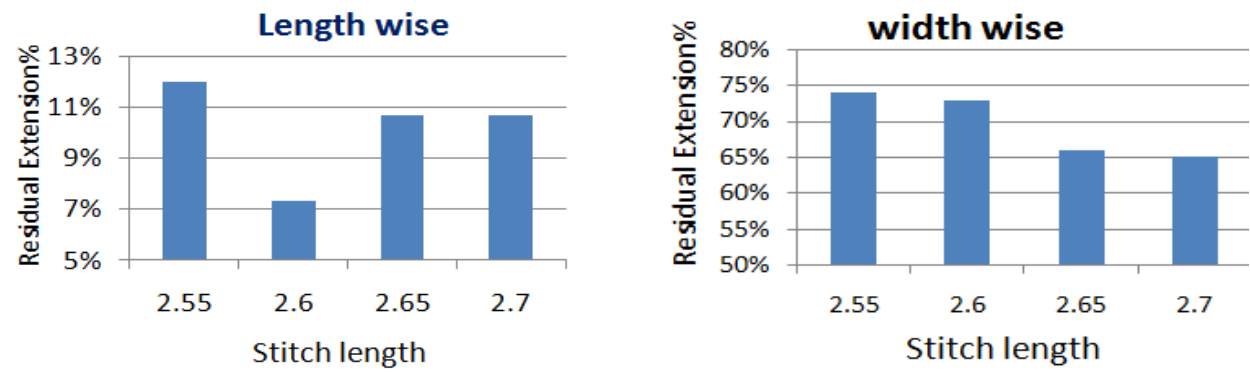

Figure 8. The effect of stitch length on the residual extension in both fabric length and widthwise after 1 minute 

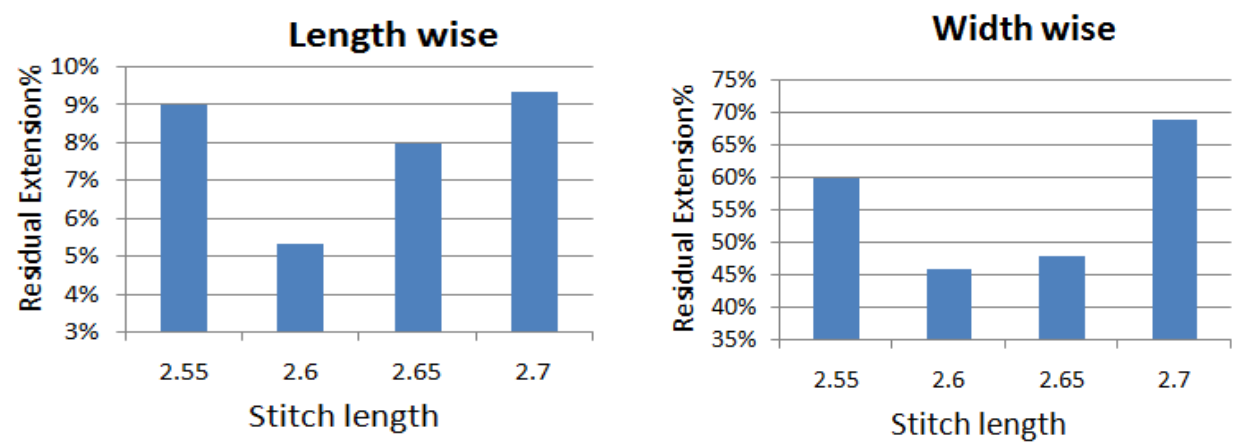

Figure 9. The influence of different stitch length on the residual extension after 30 minutes Discussion: From the view above, graphs show that the widthwise extension of $1 \times 1$ rib fabric is better than lengthwise. Also, recovery is better in lengthwise than widthwise. The better extension is achieved at stitch length $2.70 \mathrm{~mm}$ but recovery is not better here. Recovery is well in stitch length 2.6 to $2.65 \mathrm{~mm}$ at both length and widthwise.

\section{Effect of Different GSM of Same Count Ne 28/1 on Extension and Recovery of Rib Fabric}
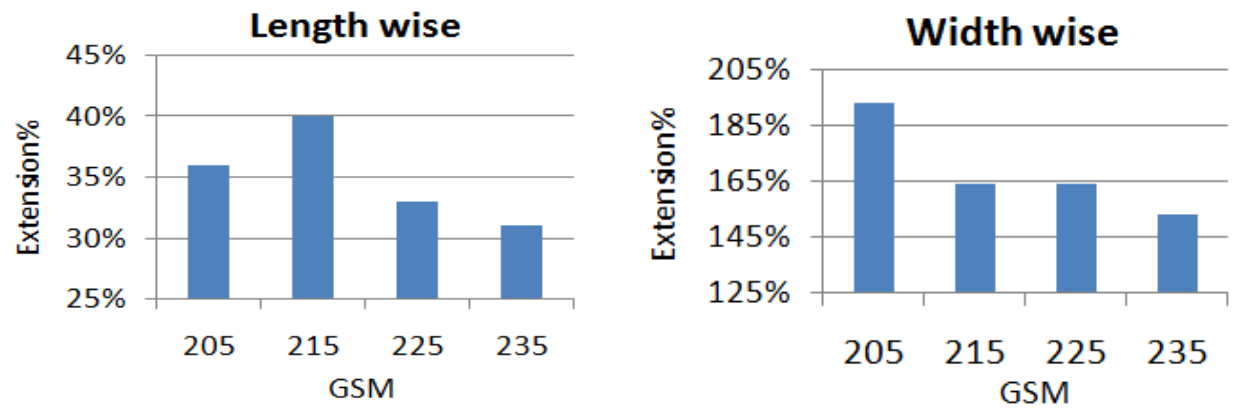

Figure 10. The changing of extension with different GSM
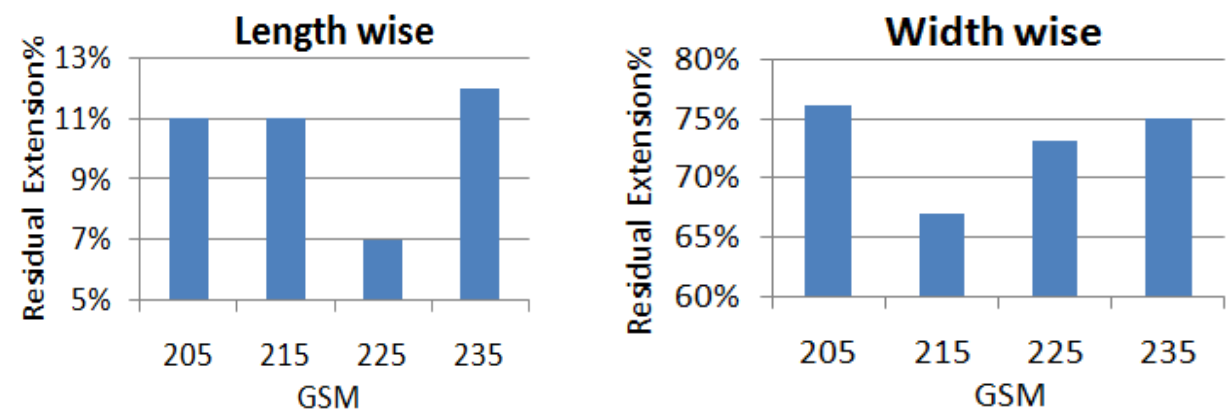

Figure 11. The influence of different GSM on the residual extension after 1 minute 

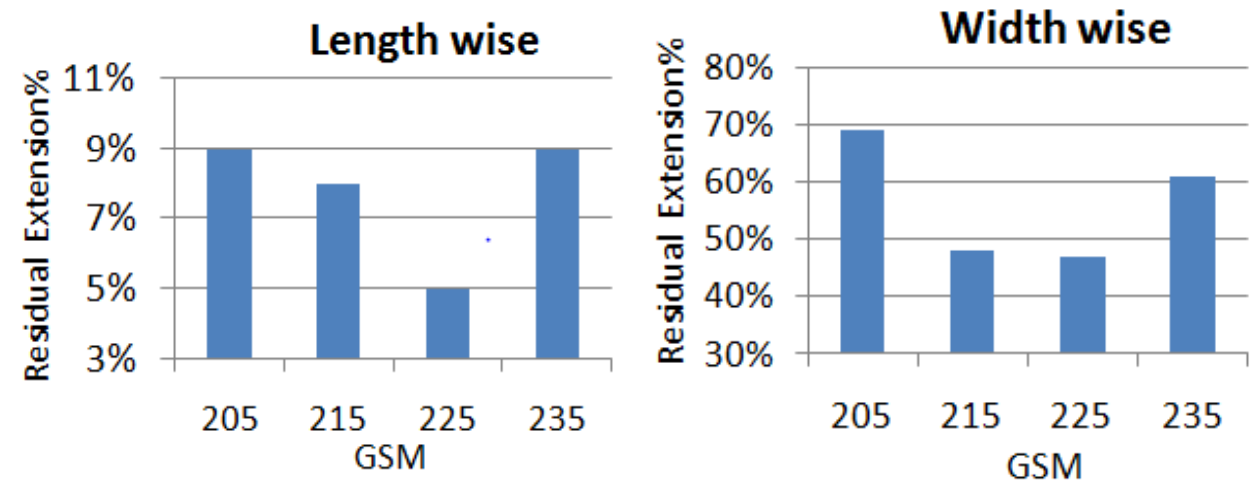

Figure 12. The effect of GSM on the residual extension in both fabric length and widthwise after 1 minute

Discussion: The above graphs show that where the extension is very high in that position, recovery is low. From the graphs, we stated that the extension and residual extension is better at GSM 215 to 225 in both length and widthwise of $1 \times 1$ rib fabrics for Ne 28/1 yarn.

The Changing of Extension and Recovery Property of Fabric with Stitch Length of Yarn Ne 30/1
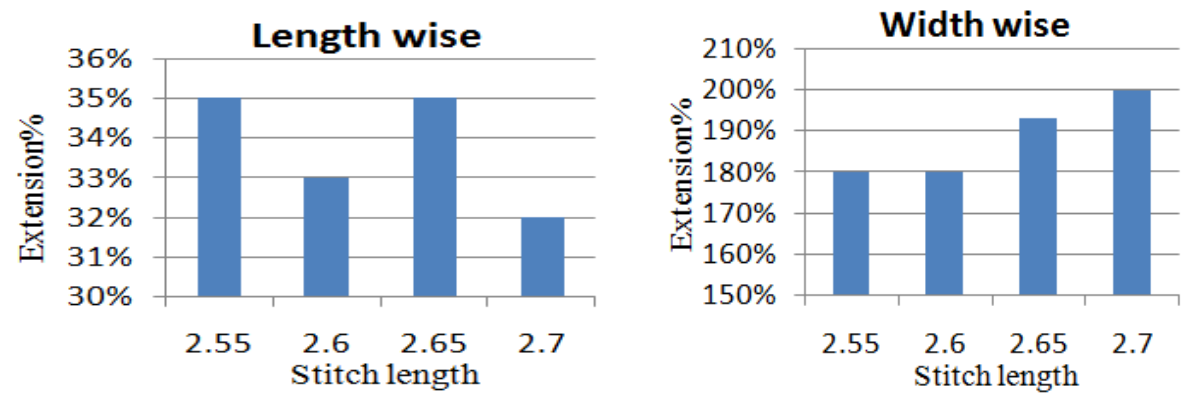

Figure 13. Stitch length Vs extension
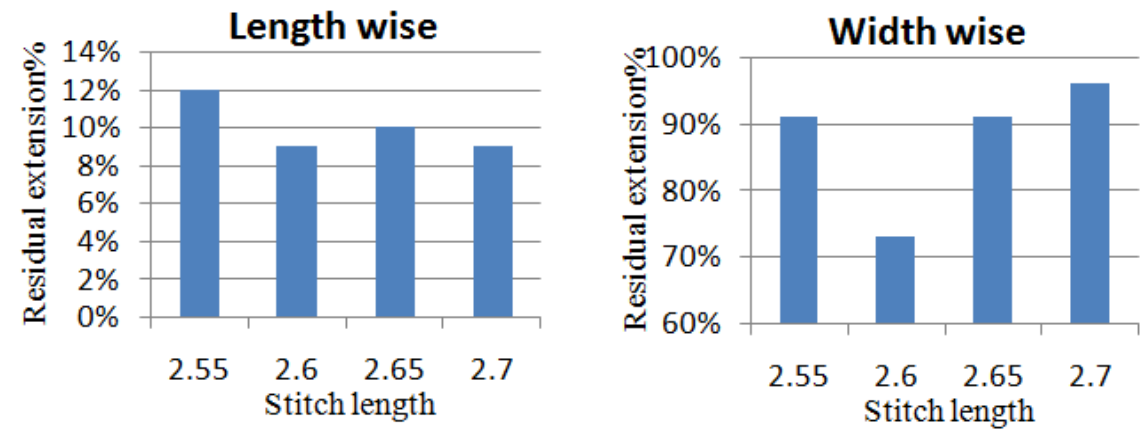

Figure 14. Effect of Stitch length on the residual extension after 1 minute 

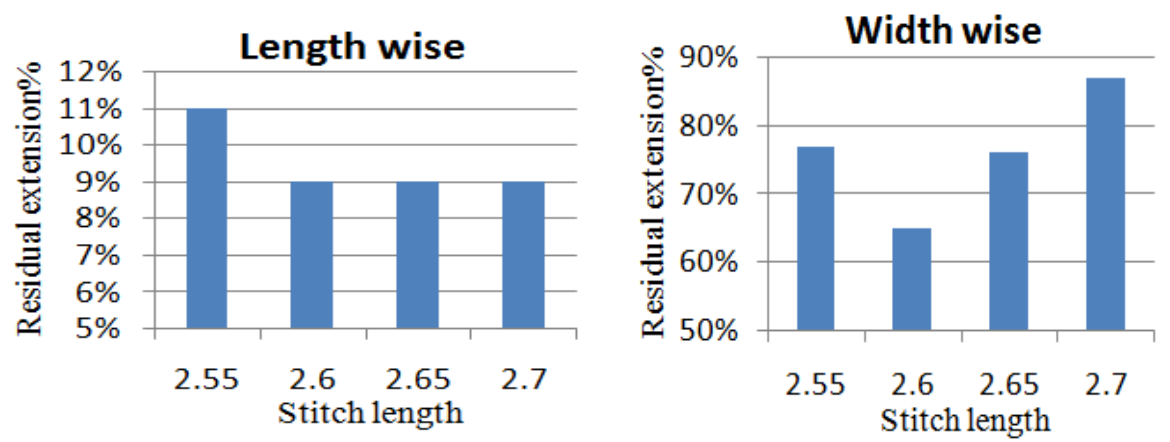

Figure 15. The changing of residual extension with stitch length after 30 minutes

Discussion: The results of the above graphs show that the length wise extension change randomly at different stitch length, but recovery is similar at 2.6, 2.65, and $2.7 \mathrm{~mm}$ stitch length. Also, widthwise extension and recovery is better at stitch length $2.6 \mathrm{~mm}$ for regular rib fabric.

Effect of Different GSM of Same Count Ne 30/1 on Extension and Recovery of Rib Fabric
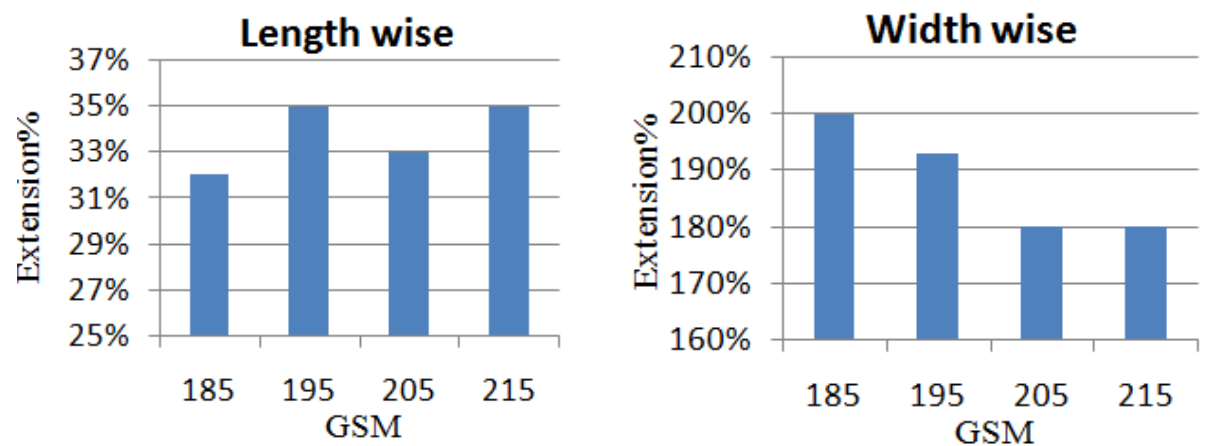

Figure 16. The changing of extension with different GSM
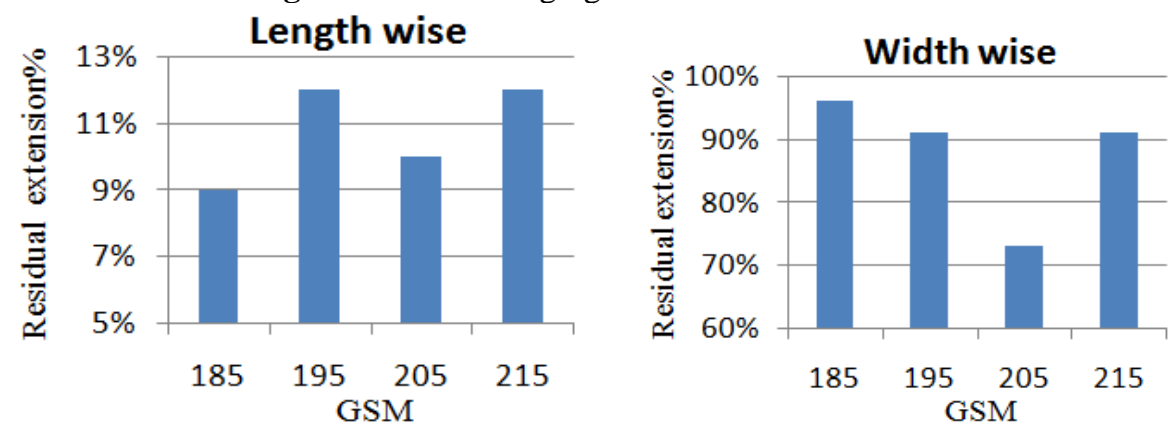

Figure 17. The influence of different GSM on the residual extension after 1 minute for $\mathrm{Ne}$ 30/1 yarn 

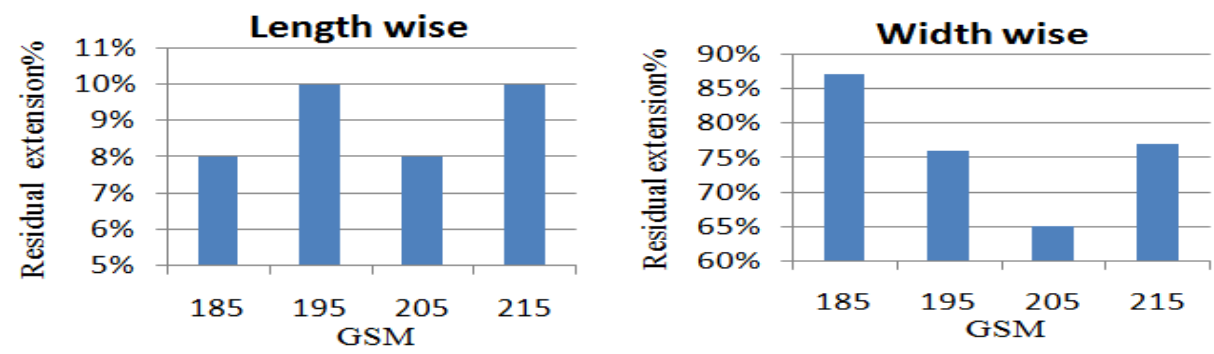

Figure 18. Effect of GSM on the residual extension of regular rib fabric at both length and widthwise after 30 minutes for $\mathrm{Ne} 30 / 1$ yarn

Discussion: From the above results, it is shown that the lengthwise extension and recovery is better at GSM 185 and 205. In the widthwise, the extension and recovery of the rib fabric are better at GSM 205 for Ne 30/1 yarn.

\section{The Change of Extension with the Stitch Length of Regular Rib Fabric}

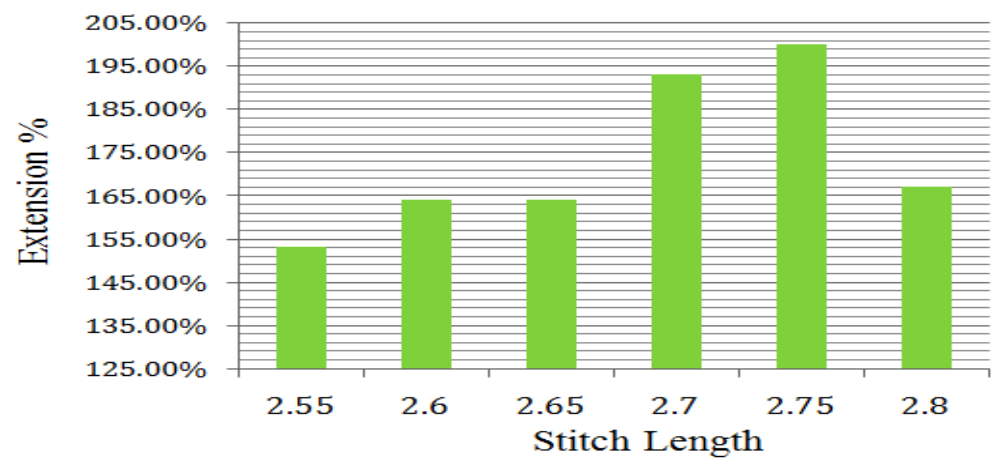

Figure 19. Relationship between stitch length Vs extension

Discussion: From the above graph, extension of rib fabric has increased with the increasing of stitch length up to a value $2.75 \mathrm{~mm}$. When exceeded, this value extension starts to fall.

Stitch Length Vs Recovery of Regular Rib Fabric

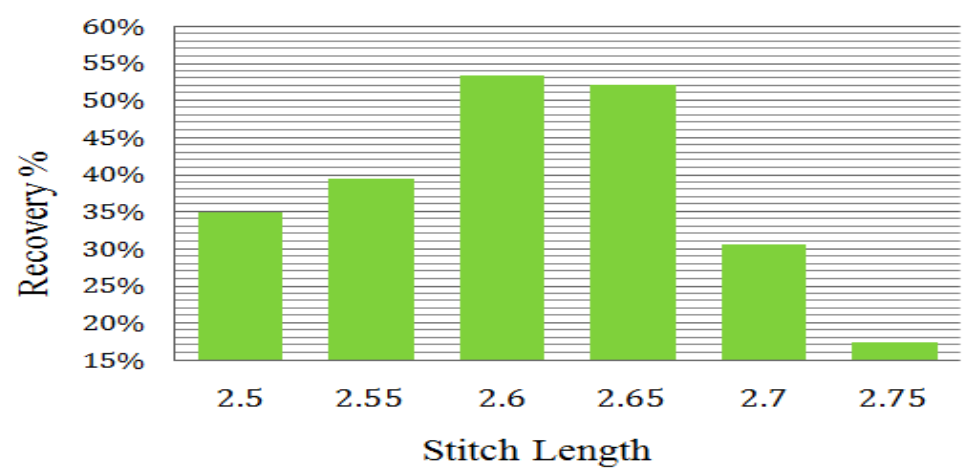

Figure 20. The change of recovery of rib fabric with stitch length 
Discussion: From the above result, recovery of the regular rib fabric is maximum $54 \& 53 \%$ of stitch length 2.6 and $2.65 \mathrm{~mm}$ respectively. When stitch length is increased, recovery of the fabric also increased up to a certain limit.

\section{Conclusion}

Through this experiment, researchers have identified the behaviour of a stretch property of weft knitted regular rib fabric due to variation of stitch length, GSM, and yarn count. Three different count of yarn was selected. Each of these yarns is with three to four levels of stitch length for experiment remaining the machine set up constant. Finally, the outcome was found below:

A. Stitch length is highly influenced on stretch and recovery property of the regular rib fabric. From this research, researchers also found that optimum stitch length range is 2.6 to $2.65 \mathrm{~mm}$ for $\mathrm{Ne} 28 / 1$ yarn count to get the best stretch and recovery properties of regular rib fabric.

B. GSM is also a dominating factor for this property. There are various rib fabrics which are produced with several GSM such as 180, 190, 200, 210, 220, 230, and so on. From the research findings, the range of GSM from 215 to 225 is optimum for $\mathrm{Ne} 28 / 1$ yarn count to get the best stretch and recovery properties of regular rib fabric.

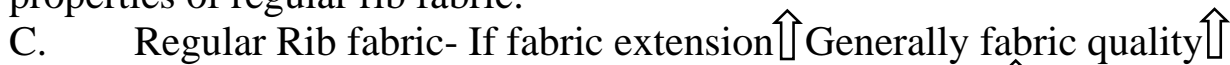

D. Regular Rib fabric- Residual extension $\sqrt{2}$ Recovery Generally fabric quality

\section{References}

1. Belal Shah Alimuzzaman (2009). Understanding Textiles For a Merchandiser. Published by BMN Foundation, Bangladesh.

2. Hamid Reza Sanjari, Dariush Semnani \& Sheikhzadeh Mohammad. (2011). Investigating the Performance of Various Relaxation Processes on the Surface Regularity and Dimensional Properties of Plain Knitted Fabrics Using the Image Processing Technique. Fibers \& Textiles in Eastern Europe, Vol. 19, No. 2 (85), 36-42.

3. Megeid, Z. M. Abdel, Al-bakry, M., and Ezzat, M. (2011). The influence of stitch length of weft knitted fabrics on the sew ability. Journal of American Science, 7 (8), 610-617.

4. Mikucioniene Daiva (2009). The Influence of Structure Parameters of Weft Knitted Fabrics on Propensity to Pilling. Materials Science (MEDŽIAGOTYRA), Vol. 15, No. 4.

5. Reza Mohammad Hosain (2017). Comparison of Properties of Single Jersey Knit Fabrics Knitted With Single and Double Ply Yarn of Same Resultant Count. European Scientific Journal, Vol.13, pp. 475. 
6. Saville, B. P. (1999). Physical Testing of Textiles. Wood Head Publishing Limited, Cambridge, England.

7. Spencer David J. (2001). Knitting Technology. Third Edition, Wood Head Publishing Limited, Cambridge, England.

8. Textiles Extension College of Textiles. Weft knitting fundamentals. North Carolina State University, Raleigh, North Carolina. 